\title{
Information Science: Science about Information, Misinformation and Disinformation
}

\author{
Miroslav Tudjman and Nives Mikelic \\ University of Zagreb, Zagreb, Croatia
}

\author{
miroslav.tudjman@zg.tel.hr
}

\begin{abstract}
Participants in interactions (particularly in interactive network media (WWW) aim to change their intentions, goals, decisions and actions - as well as those of other participants in communication. Integrity of information is therefore disturbed; changes are manifested as technical, semantic and social errors and lead to the creation of information, misinformation and disinformation. These become legitimate points of interest in Information Science. Criteria for differentiation among information, misinformation and disinformation are suggested based on their value for different participants in interaction. Therefore, the notion of relevance needs to be redefined and efficiency of information is analyzed from the point of view of participants in the communication process. Usability of information is a measure of efficiency of the information process as judged by the user. Relevance is an accepted term for measuring information usability by the user. Usefulness of information is a measure of sender's efficiency regarding the decision-making processes and actions of the information user. Usefulness is a measure of the actual effect of the author (source) of information on the choice of goals, decisions and actions of the information user.
\end{abstract}

Keywords : Information Science, Information, Misinformation, Disinformation, Efficiency, Usability, Relevance, Usefulness

\section{Introduction}

Rafael Capurro is the prominent theoretician whose scientific works are crucial for understanding the epistemology of the information science (Capurro, 1978, 1985, 1992, 2000). He concludes his analysis Foundations of Information Science with the following statement: 'Information science, conceived as a hermeneutic-rhetorical discipline, studies the con-textual pragmatic dimensions within which knowledge is shared positively as information and negatively as misinformation particularly through technical forms of communication" (Cappuro, 2000). This is one of the inferences from his analyses that is based on the attitudes that the information is in its essence connected with the insight structure of human beings. Hermeneutic science, on the contrary, argues for the holistic approach to relations between a man and the world. This approach is social as well as pragmatic and people are not isolated monads. Therefore, there is no private or subjective sphere, separated from the objective one. 'Information, in an existential-hermeneutic sense, is means for thematically and situational sharing common world" (Cappuro, 2000.) According to Cappuro, information is not the ultimate product of the presentation, it is not some-

Material published as part of these proceedings, either on-line or in print, is copyrighted by Informing Science. Permission to make digital or paper copy of part or all of these works for personal or classroom use is granted without fee provided that the copies are not made or distributed for profit or commercial advantage AND that copies 1) bear this notice in full and 2) give the full citation on the first page. It is permissible to abstract these works so long as credit is given. To copy in all other cases or to republish or to post on a server or to redistribute to lists requires specific permission from the publisher at Publisher@InformingScience.org thing that is transmitted from one mind to another, nor something separated from the introverted subjectivity. Information is the founding dimension of our 'being-in-the-world-withothers" (Cappuro, 2000).

We do not want to get into the epistemological discussion about the nature of the information. Capppuro's thesis that the information science is 
Information Science: Science about Information, Misinformation and Disinformation

the science about information and misinformation is only the motive. We want to question the thesis that information science deals with information and misinformation. Do misinformation or/and disinformation really exist as a subject matter of the information documentation practice? Are misinformation and disinformation what we are dealing with in information systems and databases? How can we theoretically distinguish information from misinformation, or information from disinformation? If relevancy is the measure of efficiency in the process of communication, how can we measure (in)efficiency of information, disinformation and misinformation in the same process?

\section{On the Terminology}

Cappuro already noticed in his article that in English word information carries many meanings, while there are almost no references to its negative forms, i.e. to the meaning of misinformation. Schrader gives negative form, misinformation, and also its derivatives: 'lies, propaganda, misrepresentation, gossip, delusion, hallucination, illusion, mistake, concealment, distortion, embellishment, innuendo, deception' (Cappuro, 2000).

In Croatian language, negative form for information hardly exists. There are some foreign words and neologisms, but there is no conventional expression for the word misinformation. Misinformation is translated as pogrešna obavijest (Bujas, 1999).

English expression misinformation is used in the place of a mistaken information, and/or misleading information. Misinformation did not necessarily spring up with the intention to deceive or to delude the user, although in some specialized dictionaries, (for example in the FBI terminology) it is stated that misinformation is the information "prepared by some intelligence service with the aim to misdirect, delude, derange or undermine the confidence of individuals, organizations or governments" (B.W. Watson, 1990.)

On the other hand, disinformation is "intentionally mistaken information with the purpose of harming the receiver by the information provider; seducing into the wrong-doing, delusion" (Klaic, 1978.)

Disinformation in English is of Russian origin (dezinformatsiya) and it is used in the meaning of intentionally falsified information, particularly launched by one government for another or for the public. Intelligence services define disinformation in a similar way: "the term is used in secret and hardly covered intelligence operations to describe falsified and misrepresented evidence used to discredit the opponent". (B.W.Watson, 1990).

We are suggesting the following terms to be used in Croatian: pogrešna obavijest (mistaken information) for misinformation and protuobavijest (counter information) for disinformation.

Misinformation (pogrešna obavijest) is a would-be information not necessarily given with a purpose to mislead the user. Synonyms pseudoinformation and quasiinformation could also be used for the same purpose. In compound words, the prefix pseudo (Gk. Pseudos-lie) denotes false, quasi, would-be, falsehood, dubiousness, something pretended. Prefix quasi, before the word, denotes "as if", "pretended", "supposed" (Klaic, 1978.)

That is why the expression misinformation (pogrešna obavijest) can be used in the meaning of incorrect, inaccurate, distorted, would-be information.

Disinformation (protuobavijest) is intentionally deputed mistaken information with the purpose to mislead the user. The inaccurate, false data are intentionally being delivered to the opponent instead of the correct information. According to Djordjevic, disinformation is the false information or inaccurate data. It can be invented news, partially inaccurate or distorted news. It is used if the message is based on the contradictory data, on real conditions and if acceptable by those who it is provided for (Djordjevic, 1986). Synonyms for disinformation are counter information, contra information and antiinformation. 
Propaganda is not the disinformation and it cannot even be categorized as the misinformation, although some of the authors include it in the negative forms of information (Cappuro, 2000). Relations and differences among misinformation, propaganda and disinformation should be looked for on the theoretic and not semantic level.

We start from the hypothesis that the misinformation, propaganda and disinformation are consequences of accidental or intentional handling with information in communicational process. In the process of communication, information is being exchanged between the source and destination. Misinformation proceeds the interruption of the data integrity in communication. Disinformation is preceded by the manipulations over the source, i.e. it is a result of the authenticity of the data authorship manipulation. Propaganda, on the contrary, aims to manipulate the attitudes of the user, i.e. aims on influencing the interests of users.

\section{Criteria for Distinguishing Information from Misinformation and Disinformation}

Information, misinformation and disinformation have not until recently been the subject of the theoretical research in information science. Today, Internet and web sites offer not only trusted and up-to-date information but also those that hold delusions and deceptions. Therefore, it is an imperative to restore the criteria for distinguishing information from misinformation and disinformation, especially on the Internet.

D. Tarcza and A. Buker (2001) offer the following criteria for distinguishing web sites that offer information, misinformation and disinformation:

- Informational web sites give the factual information. They prove the authorship, point at the source and at the owner of the information and they have valid information; those information are accurate, without errors and subjectivity, and completely up-to-date.

- Misinformations bring confusion and disorder because they are misrepresented, opposite to the previous information or modified in the communicational process. Misinformation carry errors and out-of-date subjective information. They are not always intentional attempt to convince in the incorrectness, because they express views that can be extremely subjective.

- Disinformations intentionally want to misdirect, deceive or delude. It is not clear who the actual author is. There is no contact address and as a rule, there is no actual reference to the information source, no date when it is written or updated, nor a description of its author.

D. Tarcza and A. Buker (2001) also offer the following five criteria for evaluation of the information on the web:

1. Authority

2. Accuracy

3. Objectivity

4. Currency

5. Coverage

In their paper, D. Tarcza and A. Buker (2001) do not offer theoretical explanation of their classification. That is why their classification, following the five above-mentioned criteria, is primarily pragmatic and descriptive. (Table 1: the classifications which is the result of our summarization of their thesis.) 


\begin{tabular}{|c|c|c|c|c|c|}
\hline & AUTHORITY & ACCURACY & OBJECTIVITY & CURRENCY & COVERAGE \\
\hline Information & $\begin{array}{l}\text { Authors and } \\
\text { sponsors are } \\
\text { known; further } \\
\text { more, there are } \\
\text { contact ad- } \\
\text { dresses, and even } \\
\text { warnings for the } \\
\text { copyright protec- } \\
\text { tion. }\end{array}$ & $\begin{array}{l}\text { Information } \\
\text { comprises fac- } \\
\text { tual data; data is } \\
\text { represented in } \\
\text { the way that it } \\
\text { can be authenti- } \\
\text { cated. }\end{array}$ & $\begin{array}{l}\text { Information is } \\
\text { complete, intel- } \\
\text { ligible, timely, } \\
\text { accurate and } \\
\text { unprejudiced. }\end{array}$ & $\begin{array}{l}\text { Data about } \\
\text { the informa- } \\
\text { tion source, } \\
\text { time and } \\
\text { place of its } \\
\text { origin and } \\
\text { update are } \\
\text { complete. }\end{array}$ & $\begin{array}{l}\text { Communi- } \\
\text { cation func- } \\
\text { tions; there } \\
\text { are contact } \\
\text { addresses } \\
\text { and links to } \\
\text { other sites } \\
\text { or web } \\
\text { pages. }\end{array}$ \\
\hline Misinformation & $\begin{array}{l}\text { It is not clear } \\
\text { who the sponsor } \\
\text { of the web site is, } \\
\text { who owns it or } \\
\text { who the author is. }\end{array}$ & $\begin{array}{l}\text { Information } \\
\text { does not contain } \\
\text { particular evi- } \\
\text { dence about the } \\
\text { represented } \\
\text { data; data can- } \\
\text { not be checked. }\end{array}$ & $\begin{array}{l}\text { Information is } \\
\text { not objective; it } \\
\text { contains au- } \\
\text { thor's personal } \\
\text { opinions and } \\
\text { therefore is } \\
\text { prejudicial. }\end{array}$ & $\begin{array}{l}\text { Data about } \\
\text { the informa- } \\
\text { tion source, } \\
\text { time and } \\
\text { place of its } \\
\text { origin are in- } \\
\text { complete or } \\
\text { out-of-date. }\end{array}$ & $\begin{array}{l}\text { Communi- } \\
\text { cation func- } \\
\text { tions; there } \\
\text { are contact } \\
\text { addresses } \\
\text { and links to } \\
\text { other sites } \\
\text { (web } \\
\text { pages), but } \\
\text { they are } \\
\text { sometimes } \\
\text { broken. }\end{array}$ \\
\hline Disinformation & $\begin{array}{l}\text { The real author } \\
\text { of the web site is } \\
\text { unknown and } \\
\text { there is no con- } \\
\text { tact address }\end{array}$ & $\begin{array}{l}\text { Information } \\
\text { does not contain } \\
\text { actual, approved } \\
\text { facts; informa- } \\
\text { tion comprises } \\
\text { false and inac- } \\
\text { curate data. }\end{array}$ & $\begin{array}{l}\text { Information is } \\
\text { not factual; it } \\
\text { strives to mis- } \\
\text { lead the user } \\
\text { regarding the } \\
\text { content of the } \\
\text { information. }\end{array}$ & $\begin{array}{l}\text { Data about } \\
\text { the informa- } \\
\text { tion source, } \\
\text { time and } \\
\text { place of its } \\
\text { origin do not } \\
\text { exist or they } \\
\text { are not up- } \\
\text { dated. }\end{array}$ & $\begin{array}{l}\text { Communi- } \\
\text { cation does } \\
\text { not func- } \\
\text { tion; future } \\
\text { interaction } \\
\text { with the } \\
\text { web site is } \\
\text { not clear. }\end{array}$ \\
\hline
\end{tabular}

Table 1: Relation among 5 criteria for evaluation of the information on the web

\section{On the Information's Integrity}

Theoretical explanation of the integrity of information should be started with the classification of the process in which information is exchanged between sender and receiver (end user). Standard library, documentation and information theories start with the postulation that the information (data, documents) should be collected at the source, transmitted, processed, stored, and finally distributed to the users (T.Saracevic, J.B.Wood (1981), M.Buckland (1994)).

However, even long before the information science was founded, it was known that the symbolic, semantic and pragmatic dimensions designate the completeness of the information. That division is also applicable in mathematical theory of information by C. Shannon and W. Weaver (1949), who empha- 
sized that they are not concerned with semantic or pragmatic dimension of the information, but only with the transmission of the signal from the source to its destination. Following that attitude, completeness of the information in computer science and in informatics is reduced to only one technical dimension: transmission of the signal, i.e. data processing without going any deeper into its semantic and pragmatic meanings.

In theory, there are series of attempts of defining the integrity of information. Fuchs and Hofkirchner strive to define the Unify Theory of Information - UTI (Fuchs, C., Hofkirchener, W., 2002). Proceeding from the thesis that in the process of single information development, data, knowledge and wisdom should be distinguished, i.e. data are shaped on the basis of signal reception. Data is a starting point for shaping the knowledge necessary for evaluation and decision-making, or in other words, for wisdom.

According to the Unify Theory of Information, cognition is always connected with the outside world: the subject is always determined in accordance with events and conditions in its surroundings. Single information is the complete information, with three levels: data, knowledge and wisdom.

- On the first level, signals are perceived from the environment. Perception is the act that comprises reception and conception of the signal; the new unit is called data.

- On the second level, data are interpreted, i.e. meaning is added to the data and knowledge is shaped. Interpretation is the process of intermezzo between projection and introjection. Existing knowledge is applied to data in projection, that is, system is projected to reality. In introjection, new data are interpreted in relation to the existing knowledge structure, from which the new knowledge structure rises, in other words, the system introjects reality into its structure. Projection and introjection are infinite agitators of cognition. It can be said that the environment never determines cognition in full, but also that knowledge is not shaped completely autonomously, nor completely independently from the environment. Knowledge is the consequence of data interpretation and that process includes experience and facts.

- On the third level, the subject puts knowledge into context of its aims, it evaluates the knowledge based on the single information that contains values, norms, rules, opinions, ideas or beliefs. This process begins in the situation when subject has to act with a purpose of solving a problem. In those situations, knowledge is evaluated and meaning is added to it. The evaluation process comprises description and prescription. Description is the application of the existing rules of evaluation in the problem solving process during which individual values and norms are not changed. Prescription is the process during which new individual values, norms, rules and beliefs, based on the new experiences, appear.

According to the Fuchs's and Hofkirchner's explanation of the single information, the following can be concluded:

a) Data is a result of the reception and perception of the signal that enters the system

b) Knowledge is a result derived from interpretation of the sign and cognition object relations

c) Meaning and value of the single information are determined by the relation between action (decision) and the problem that cognitive subject is confronted with.

However, Fuchs and Hofkirchner draw our attention with good reason to the social information, which proceeds from the social activity. Social relations are being established during the mutual activity of the two individual actors. It is believed that social cooperation exists when social relations and social interaction of individual, if of benefit, are established. Norms, values, rules, and laws established during the social relation are considered social information since individuals have to share the common opinion in order to interpret and construct reality. This insures the basis for their social activity and interaction. 
Information Science: Science about Information, Misinformation and Disinformation

The following assertion, given by Fuchs and Hofkirchner, is important for interpretation of the information integrity: 'Social action is necessary, but not sufficient condition for establishment of the social relation because social activity does not require the relation between factors: the first factor can relate to activity of the second, but the second does not have to relate to the activity of the first" (Fuchs, C., Hofkirchener, W., 2002).

Now, we can return to our theoretical interpretation of information, misinformation and disinformation differences.

Integrity of information, according to the Unify Theory of Information, is ensured by the unity of data and the meaning of information. Now, complete information is the one that precisely receives and perceives the signals, properly interprets data and purposefully applies the knowledge with the aim to solve the problem.

Interruption of the information's integrity may happen on 3 levels:

a) data integrity level

b) meaning integrity level

c) decision- making level

In the first case, error in transmission and/or reception of the signal happens.

In the second case, during the interpretation, two kinds of errors are possible. Either the sign misdirects to the cognitive object or it directs to the wrong cognitive object.

In the third case, wrong relation between information and the action is established, whether wrong evaluations are based on the misinformation and/or wrong decisions. It is obvious that the second level of the error implies the first one, while the third level implies both second and first. Namely, wrong data are basis for the wrong interpretation while the wrong interpretations lead to the wrong evaluations and decisions.

Having in mind the consistency and integrity of information during the process of shaping the data all the way to the meaning and decision-making, integrity of the information observes information primarily from the cognitive function point of view. The Unify Theory of Information interprets the information as a result of the cognitive actions that include perception, interpretation and evaluation.

Therefore, the interruption of the integrity of information is declared as:

a) Technical error - error in the transfer or error in the data perception. Technical error results in wrong data, or in other words, in misinformation.

b) Semantic error - error in the addition of the meaning or interpretation error. Wrong meanings shape misinformation but also misunderstanding in the social relations. That is why semantic errors might be the base for disinformation.

c) Social error - error in evaluation and use of the information. Wrong data and wrong interpretations result in wrong evaluation of the problem, wrong determining of the aim, and/or wrong decision and action. Attaining the errors in social acting and decision-making is the main task and the main intention of the disinformation.

No matter how this classification of the integrity of information from the cognitive function point of view, may help understanding the nature of information, misinformation and disinformation, this approach does not provide the complete answer to questions how and why it is possible to structure the misinformation and disinformation. 
Let us go back to the main differences between misinformation and disinformation (Table 2). As represented by Tarcza and Buker (2001), the origin of disinformation or manipulation with the information is not in the cognitive process, but in the manipulation with:

a) Information source: source is unknown,

b) Author of the information: the author is unknown,

c) Information sender: communication with the sender is not possible.

Consequently, we do not need to seek for the inception of misinformation and disinformation primarily in the cognitive but rather in the process of communication. Therefore, we return to our thesis that the information is symbolic product, determined by the cognitive, communication, information and memory function (M. Tudjman, 1990, 1991).

Information as a symbolic product is developing as a whole but particular functions that constitute it are inseparably linked. Interfuncional links and relations are not constant, unimportant and negligible from the point of view of knowledge management. It is precisely the change of the interfuncional links that is the main feature and content of the computerization and that means, changing the functional knowledge management (M. Tudjman, 1990, pp.120).

\begin{tabular}{|l|l|l|}
\hline & \multicolumn{1}{|c|}{ MISINFORMATION } & \multicolumn{1}{|c|}{ DISINFROMATION } \\
\hline Authority & $\begin{array}{l}\text { Undefined sponsor } \\
\text { There are no particular evidences } \\
\text { or facts }\end{array}$ & $\begin{array}{l}\text { It is not clear who the real author is } \\
\text { Information is not verified by facts }\end{array}$ \\
\hline Objectivity & $\begin{array}{l}\text { Personal point of view } \\
\text { Currency }\end{array}$ & $\begin{array}{l}\text { Out-of-date } \\
\text { Real sources are not revealed } \\
\text { are missing }\end{array}$ \\
\hline Coverage & $\begin{array}{l}\text { Communication is functioning } \\
\text { partially }\end{array}$ & $\begin{array}{l}\text { Interaction is not possible } \\
\text { Table 2: The main differences between misinformation and disinformation }\end{array}$ \\
\hline
\end{tabular}

\section{Forms of Communication and Types of Information}

Till the appearance of computers, knowledge was recorded only in the analog form and publication was the only media for knowledge exchange. The term publication is used as a generic term for all kinds of publications (monographs, periodicals, serial publications, etc.) and also for all kinds of papers contained in the publications (articles, reviews, essays, etc.). Publication transfers the knowledge in the ana$\log$ form, i.e. in form of the fixed and invariable record. Knowledge is limited by the publication used as the fixed area for representing the knowledge. Book, i.e. publication, was the synonym for knowledge since Guttenberg. Why? Because the entire cognitive process, from perception and presentation to the evaluation of knowledge, is represented, comprised, and completed in the publication. Author was responsible for the finding the data source, providing the evidence and making decisions. Publication is only the multiplication of the original document. It does, however, have some additional mechanisms (publisher, editor, reviewers, etc.) that offer guarantees of authenticity and reliability of knowledge but communication function does not influence the structure of knowledge itself. The task of the communication function is to multiplicate the recorded knowledge in the way it can be distributed to the large number of users. 
Information Science: Science about Information, Misinformation and Disinformation

Collecting, processing, storage and use of the publication is the task of the documentation function. It means that the life cycle of knowledge contained in publications, is determined by creating, collecting, processing, storing and using the publication.

Publications are organized in library or documentation material's funds and the task of the information function is to insure the access to the funds or to the particular items of library or documentation material. But evaluation or estimate of the information is exclusively up to the user, his needs and common sense. User himself evaluates the information, while the whole information documentation system only insures selection and approach to publications. That is why the lifetime of publications is determined by their usage value, i.e. the number of publication's loans in the unit of time and not by its cognitive value (C.Couture-J.J.Rousseau, 1987).

Publication is a passive media (L.Floridi, 1996). Radical change of the knowledge management started out by the introduction of digital media. This change has already been announced by Shanon and Weaver in their Mathematical theory of information (1949).

They explicitly emphasized that they are dealing only with the signal transfer and not with the semantic and pragmatic dimension of information. Digital record enables data to be separated from the media, to be transferred from one media to another, or in other words, digital media enable interactive approach to their content. The result of such interactive communication is separation of data from its primary meaning. Thanks to the new opportunities of interactive communication, the primary integrity of information is broken. The information author has no longer exclusive right or surveillance over the process of information shaping, i.e. on its presentation, explanation and evaluation. Explanation and evaluation now become possible for the user. That is why information acquires the new value: it becomes relevant. Data acquires a new value for the user because it is placed in a new context and given a new meaning. Thus, relevance is defined as a "measure of efficiency in a communication process" (Saracevic, 1975) or, more accurately, relevance is a measure of the communication function just as truthfulness is a measure of the cognitive function.

Thanks to the digital media and (tele)communication technologies, record has turned into a movable text. Information in digital form can be cumulated, selected, processed, modified, applied and used for new needs. Text becomes a movable media and holder of the many different meanings. It has one primary cognitive message for the author but for the user it acquires the new communication value - information becomes relevant for some future usages.

Both author and the user are in the interaction with information, more precisely with the corpus of texts. It means they are both condemned to interpret and validate the signals they exchange: first one by artic ulating the message (cognitive information function) and second one by decoding its meaning (communication value). It means that the information organized in corpus of texts (databases, information systems, databanks, expert systems, etc.) is essentially determined by the digital media and the interactive approach.

We have already mentioned the following classification (V. Floridi, 1996):

- Passive one-way media or W-media

- Interactive two-way media or WW-media.

We can easily add one more group to this classification:

- Networked interactive (multi)media or WWW-media.

Today, the Internet is an example of WWW-networked interactive (multi)media. It is a multiple corpora of networked knowledge regarding many of its features. Lifecycle of the information on the Internet is determined by the following stages (V. Floridi , 1996): 
- Creation

- Storage

- Retrieval and

- Update.

As a result, presentation, organization, distribution, and usage of this type of information (knowledge) are totally different from the passive media (W-media) or interactive media (WW-media). We have already mentioned that it is the author who is responsible for presentation, interpretation and evaluation of the information with passive media. With the WW-interactive (multi)media, author is still responsible for the present ation but users and mediators also participate in the interpretation and evaluation process. Here, we use the term mediators in the meaning of information systems, databanks, databases and the entire information documentation infrastructure that participates in the process of collecting, storing, processing and using information.

With the WW-media, information systems, i.e. all kinds of information documentation systems, are mediators between the author (emitter) of the information and the user. These are two-way interactive systems in such a way that the author of the information and users are in the interaction with the system but not in the direct communication with feedback.

Therefore, although WW-media are organized online, there is always smaller or bigger detachment between the primary communication system and the information system, as a mediator of the primary information. Owing to that, author of the information is recognizable as a sender and responsible for the presentation of the information.

Regarding the WWW-media, authors have not lost their identity but the character of the authorship and of the information source have changed. Author entry is objectively determined, beside by the author and the corporative author, by the sponsor of the website and indirectly by the Internet service provider. The information source is no longer only one person, institution or the document, but also the Internet, service provider, web site.

With WWW-media a number of new mediators participate in the creation of the information. As a result, the number of participants who determine the authorship and information source is increased. Their constant presence in communication and interaction with the users has changed the very nature of communication. The new information source is actively present on the Internet because it generates and updates its information all by itself. Sponsors and authors of the web site are interested in the presentation of information both in the name of the author and in the name of the information source.

Knowledge corpora in WWW-systems are opened considering the number of participants shaping its corpora as well as considering the size and the quality of the presented content. Knowledge corpora on WWW-media are constantly refreshing itself. Since not only the users or mediators, but also rather the senders, maintain and update it, those parts that are not being maintained nor updated automatically become out-of-date and they die out.

WWW are networked media with the known inception and rules of conduct. Today, however, they are open systems in the true sense of the word. Regarding the information proportions, number of users, information provider, etc., the size and growth of this system is not controlled. Furthermore, the Internet is interactive media with the changeable and multiple relations among the author, service provider and the user. Each and every user may become the information provider and each author may become the user in his or her interaction there is no need for the mediator. This is possible only because the information function (function of the information organization and selection) is completely connected with the communication function (function of the knowledge dissemination and distribution). The movable text has changed into hypertext and/or multimedia text, organized in the way it can be searched and used ac- 
Information Science: Science about Information, Misinformation and Disinformation

cording to all criteria - starting with the moment it was launched. That characteristic connected and equalized the author and the user and turned them into participants in communication, where each of them strives to accomplish his communication interests and satisfy his communication needs.

In every communication, the author of the information is the active participant and with the emission of the information he wants to ensure the communication benefit for himself. Namely, communication is not end in itself, so as long as the user seeks for the relevant information to satisfy his needs and demands, information sender wants to satisfy his social and communication needs by sending the relevant information in order to achieve the goal.

However, no matter how many different types of information exist, from the sender's point of view they are not explored only because the sender in the $\mathrm{W}$ - and WW-media was the passive participant in information process. In other words, information systems dealing with $\mathrm{W}$ - and WW-media are only the mediators or aids to the primary communication systems. With the WWW-media where the communication and information processes overlap, the dividing line begins to disappear and in some fields it has already dissolved. That is why efficiency (effectiveness) of the communication system needs to be reviewed, having in mind not only the relevancy for the user but also the usefulness for the sender.

\section{Relevance in the WWW Communication}

With the appearance and development of the information retrieval systems, retrieval and insurance of the relevant information became the main task of these systems. Relevance is since then the key issue of the information science, used in analysis of the information services and as the most relevant theoretical concept for the evaluation of the information exchange and for understanding the information process. As it is the case with all other basic concepts in science, there is no consensus for one definition of the term relevance as well. Relevance is always interpreted as a measure of effectiveness of the information process with the aim to satisfy the information needs and user demands. Since some of the authors consider that the different factors that determine the process of information exchange have the crucial influence on the efficiency of the information process, different explanations of the relevance arise.

Relevance is explained from the point of view of the information system, destination, subject literature, subject knowledge, pertinence, as well as from the logic and pragmatic viewpoint (Saracevic, 1975).

Relevance (in the theory of information science) is not explained from the information sender's viewpoint. There are two essential reasons for that. The first one, as we have already mentioned, is that in the information systems dealing with W- and WW-media processing, sender (the author) of the information is not the active participant in the information exchange. Information systems are only mediators between the user and the information sender because those systems do not ensure direct communication between them.

The other reason for not exploring the interest of the information sender in the information exchange is the fact that information science in its very beginnings deals primarily with the processing of the scientific information. Indeed, information science is defined as a scientific discipline that explores the structure and the features of the scientific information (A.J.Mihajlov, R.S.Giljarevski, 1977). Although information science has not always been defined as a discipline about scientific information, it has been dealing primarily with scientific and professional information and it has been above all oriented to scientific communication from its very beginnings (Tudjman, 1990).

Scientific and professional information in their nature have to be true or aim at realizing the truth, so there was no need for challenging the communication interests of the information sender because they are considered not to have other communication intentions beside the scientific and professional interests and reasons. 
The field of information science has long time ago spread over all types of information and not only scientific and professional ones. Development of the information technology (WWW media) has caused the information and communication systems to connect information senders and users in such a way that they both try to accomplish their interests during the information exchange. Information processes and systems became the part of the actual social relations and means for the social interaction.

Therefore, information processes are today, more then ever before ridden with the enormous amount of information, as well as with the disinformation and misinformation. Disinformation and misinformation are no longer only system errors or human mistakes but also the result of institutional efforts and endeavors. As this is not the subject of this paper, we state only a few notions. Today, marketing and propaganda are the component part of many disciplines. Propaganda is by some authors considered to be the "Twin Sister of Disinformation", because it is, like disinformation, "War with Words"; indeed, as long as disinformation knows no competition, propaganda keeps on living on it (Liminski, 2002).

During the Cold War, institutions like radio stations, publish houses, etc. that were responsible for the marketing of misinformation and disinformation were established on both sides of the "iron curtain". Today, there are many books and papers written on this subject (See E.J.Epstein, 1989).

Today as well, some governments form, more or less openly, the agencies through which they want to influence the public opinion and world's politicians. Military forces and intelligence services of many countries have developed special regulations and programs for disinforming. In order to avoid the high intensity conflicts, they lead the low intensity conflicts using the mass media.

It is not only political, military, and business information that are the subject of misinformation and disinformation but also data on ecology and climate (M. Swords, 2002). Because of these trends, some authors are alr eady announcing that the "Information Era" is being replaced with "Disinformation Era". It is of a great significance that D.J.Rothkopf (1999) starts his article with the following words: 'Do not believe anyone.'

\section{Relevance from the Sender's Viewpoint}

Certainly there must be theoretical and pragmatical reasons for reinvestigating the value of information exchanged in information-communication systems and to reconsider the efficiency of information, not only from the user's point of view, but also from the sender's (author's) vie wpoint.

We proceed from the thesis set by A. Kovacz (1997) that efficiency of intelligence or information can be judged from two different viewpoints: usability and usefulness. Although we have already used these criteria (M.Tudjman, 2002) for the analyses of information and intelligence, we will apply the same classification on the new explanation of the concept of relevance.

No matter what type of information we are dealing with (information, misinformation or disinformation), efficiency can be evaluated from the point of view of all the participants in the communication process.

Usability of information is a measure of communication efficiency in the information process. In this process, information came to the end user through the services that collected, processed, analyzed, and disseminated them. Usability is the measure of efficiency of information service evaluated by the user. Usability of information is the matter of intrinsic and subjective evaluation of the information user.

Usability describes a degree of satisfying the user's need for information at the moment of its inception or at the moment when information was delivered to the user. In information science, relevance is the accepted term for measuring information usability by the user.

Usability is measured by means of relevance. Values of the relevant information are timeliness, reliability and accuracy of data, detailness and convenience of the classification, and mode of presentation of 
Information Science: Science about Information, Misinformation and Disinformation

information. In other words, value of the relevant information is judged by the criteria of the authorship, accuracy, objectivity, promptness and properness.

Relevant information are those information that are usable for the user. Usability is indeed the measure of potential. Usability of information directs the user to the possible options offered on the basis of the new available data. Despite the conceptions they offer and their usability, there are many reasons why information need not be used. For example, the user is not able or is not allowed to use the available information for the lack of means to reach the goals or for the lack of social, political, public, or some other kind of support to carry out the decision, for the lack of courage or firmness to make a decision, etc.

Usefulness of information is a measure of the actual efficiency of the information process. Usefulness of information can be evaluated on the basis of the objective criteria, but only post-facto, i.e. only after they were actually used by the user.

A. Kovacz supports five criteria for measuring the usefulness of information, although he is aware that these five criteria are not consistent since they overlap. He believes that the third criterion comprises the first one. According to A. Kovacz, information is useful if it:

- leads the information user to change the previously made decision or to change the aim of the action;

- enables different (better) option for the implementation of the already made decision or the aim of the action;

- plays the key role in decision making (implementation of the action or the decision for its implementation is based on the given information);

- forces the opponent to change or modify the implementation of his politics or actions;

- improves the effects of the politics led by the user or reduce the disadvantageous impacts of the opponent's actions, i.e. of the other social protagonists.

Objection that can be raised regarding the arguments and criteria, quoted according to A. Kovacz, should be sustained. Those arguments and criteria relate only to one special aspect of the information and they cannot be applied in the evaluation of the usefulness of all information processes.

However, it is not of major importance for our analysis if the previous arguments are of universal or particular importance (i.e. if they relate to all or some of the information systems and processes). It is rather crucial to notice two things: first, the usefulness of information is the actual measure for the evaluation of the application value of the (particular) information and second, the usefulness of information is determined not only by the user's decision but also by his intentions and interests. Consequently, both the user and the sender strive to change the intentions and the decisions of the other. Why? Because they are in the interaction (especially in WWW-media) and they constantly change their social rules (usersender) in the communication process.

Stated criteria for the explanation of the usefulness of information proceed from the theoretical thesis that the decision making process is a black box with information as input and with actions as output. According to this model, information is efficient (or useful) if its input changes the output, i.e. if it influences the change or the implementation of the action.

Although the possibility of measuring the information from the efficiency's viewpoint is very questionable, the whole theory that both relevance and usefulness of information need to be measured, is of a great importance. 
If relevance remains the key term of information science as a measure of efficiency of the communication process from the user's viewpoint, then the usefulness of the information is a measure of efficiency of the information process from the sender's viewpoint.

The criterion of information usefulness is a measure of sender's efficiency regarding the decisionmaking processes and actions of the information user.

According to the criteria of usefulness, the actual effect of the information author (source) on the selection of the goals and decisions is measured.

It is obvious that, with the objective and accurate information, values of information relevance and usefulness will overlap and they may be used as synonyms.

However, usefulness of misinformation and disinformation is for the user inversely proportionate to the information relevance.

\section{Conclusion}

In the beginning of this paper we wanted to check out the thesis if the subjects of the information science are information and misinformation. Do misinformation and disinformation as a real subject of the information documentation practice really exist?

Are we dealing with misinformation and disinformation in the information systems and databases, and how can we theoretically distinguish information from misinformation, and/or the information from disinformation? If the relevance is a measure of usability in the communication process, how can we measure inefficiency of the information, misinformation and disinformation in the communication process?

Information science cannot neglect the fact that the information exchange is a social relation and a form of social action whose participants often have opposite interests. Participants in the interaction strive to change the intentions, goals, decisions and actions - not just their own, but also of other participants with whom they might be in some kind of connection.

That is why information science has to start exploring the information relevance from the user's vie wpoint, as well as from the point of view of senders and all the other participants in the interaction.

Available information technologies determine the type of interaction between participants in the process of creation, exchange and knowledge usage. Communication patterns influence the knowledge structure and organization. Memory function (function of knowledge storage) determines the mode of presentation and the type of media. That is why cognitive function is a necessary but not the sufficient condition for understanding the knowledge structure and management.

Depending on the application of new technologies and development of information, documentation, and communication functions, we described three different communication patterns, i.e. three dominant media.

Passive media (W), interactive media (WW), and networked media (WWW) offer three different types of information, three different communication patterns, three different modes of interaction between participants in the knowledge exchange, and three different types of the information interpretation.

WWW-media enables the interaction between the information author and the user who exchange their roles (author-user) and have different and often opposite interests that they are striving to achieve. In this interaction, a number of new participants, unknown in previous media, mediate.

Therefore, it is necessary to accept the fact that information, misinformation and disinformation circle in information and communication systems and that all types of information are subjects of the information science. The task is to build criteria and standards for recognition and evaluation of misinformation and disinformation in order to protect the users, as well as the information systems. Information science has 
Information Science: Science about Information, Misinformation and Disinformation

to begin building mechanisms for the protection of the information and communication processes from the contamination with the misinformation and disinformation.

In order to realize these tasks, information science has to redefine some of the basic terms. We have already warned that dominate media determines knowledge structure and organization. This means that knowledge lifecycle and lifetime are not defined by the same functions in different media. Basic terms such as information, author, information sender, information source, information destination, relevance, etc. become inaccurate, unclear, undetermined and incomplete when used in the analysis of new (WWW) media and new communication patterns.

In this paper we have analyzed information, misinformation and disinformation, not only from the viewpoint of the cognitive function, but also from the information function and communication function viewpoints.

We can verify Capurro's thesis that information, misinformation and disinformation are legitimate and indispensable subjects of information science, especially now when all three types dominate the WWW media.

That is why we started to explore the efficiency of information from the viewpoint of all the participants in the communication process. Efficiency can be evaluated depending on usability and usefulness.

Usability of information is a measure of efficiency of the information process as evaluated by the user. Relevance is an accepted term for measuring information usability by the user. Our thesis is that the usefulness of information is a measure of sender's efficiency regarding the decision-making processes and actions of the information user. Usefulness is a measure, but not the scale or the unit of measure; measure is only the relation, which has to be measured with some scale or units of measure.

That is why our classification does not offer final solutions. This classification indicates that the relevance, until now the fundamental term in information science, is only the measure of information efficiency. Information can also be measured from the information usefulness viewpoint. If that is so, then the new research and development areas, dealing with the fundamental terms in information science, arise.

\section{References}

Buckland, M. (1983). Library Services in Theory and Context. New York: Pergamon Press

Bujas, Ž. (1999). Veliki englesko-hrvatski rjecnik. Zagreb: Nakladni zavod Globus.

Capurro, R. (1978). Information: Ein Beitrag zur etymologischen und ideengeschichtlichen Begrundungen des Informationsbegriffs. Munchen: K. G. Saur.

Capurro, R. (1985). Epistemology and Information Science. Stockholm: Royal Institute of Technology Library.

Capurro, R. (1992). What is Information Science for: A Philosophical Reflections. In Vakkari, P., Cronin, B. (Eds). Conceptions of Library and Information Science: Historical, Emp irical and Theoretical Perspectives (pp. 82-98). London: Taylor Graham.

Capurro, R. Foundations of Information Science: Review and Perspectives. Retrieved May 20, 2002 from the http://www.capurro.de/tampere91.htm

Couture, C., Rousseau, J.Y. (1987). The Life of a Document. Montreal: Vehicule Press.

Đordevic, O. (1986). Leksikon bezbednosti. Beograd: Partizanska knjiga.

Epstein, E. J. (1989). Deception: The Invisible War Between KGB and the CIA. New York: Simon \& Schuster.

Floridi, L. (1996). Brave.Net.World: The Internet as a Disinformation Superhighway. Oxford: Wolfson College.

Fuchs, C., Hofkirchener, W. Information in Social Systems. Retrieved April 04, 2002 from the http://igw.tuwien.ac.at/igw/menschen/hofkirchner/papers/InfoScience/dresden/dresden.html 
Klaic, B. (1978). Rjecnik stranih rijeci. Zagreb: Matica Hrvatska.

Kovacz, A. (1997). Using Intelligence. Intelligence and National Security, 4(12), 145-164.

Liminski, J. Desinformation im modernen 'Krieg mit Worten', Retrieved May 15, 2002 from the http://www.konservativ.de/epoche/

Mihajlov, A. I., Giljarevskij, R. S. (1997). Uvod u informatiku/dokumentaciju. Zagreb: Referalni centar Sveucilišta u Zagrebu.

New Shorter Oxford English Dictionary (NOED). (1997). Oxford: Oxford University Press.

Saracevic, T. (1975). Relevance: A Review of and a Framework for Thinking on the Notion in Information Science. Journal of ASIS, 26(6), 321-343.

Saracevic, T., Wood J.B. (1981). Consolidation of Information: A Handbook on Evaluation, Restructuring and Repackaging of Scientific and Technical Information. Paris: UNESCO, PGI-81/WS/16.

Shannon,C., Weaver, W. (1949). The Mathematical Theory of Communication. Urbana: University of Illinois Press.

Swords, M. Global Climate Change: Information, Misinformation, and Disinformation. Retrieved July 15,2002 from the http://www.wmich.edu/environmental-studies/Writings/swords3.html

Tudjman, M. (1990). Obavijest i znanje. Zagreb: Zavod za informacijske studije.

Tudjman, M. (1990). Teorija informacijske znanosti. Zagreb: Informator.

Tudjman, M. (1991). Culture and Information Society: The Japanese Way. Information Processing and Management, 27(23), 229-243.

Tudjman, M. (2002). Informacijska znanost i izvjesnice: Prilozi razumijevanju teorijskih odrednica znanja, obavijesti i izvjesnica u informacijskoj znanosti. Informatologia, 35, 4(2002), 244-251.

Watson, B. W., Watson, S. M., Hopple G. W. (ed.) (1990). United States Intelligence: An Encyclopedia. New York/London: Garland Publishing, Inc. 